\title{
Magnetic recording of the Cenozoic oceanic crustal accretion and evolution of the South China Sea basin
}

\author{
LI ChunFeng ${ }^{*} \&$ SONG TaoRan \\ State Key Laboratory of Marine Geology, Tongji University, Shanghai 200092, China
}

Received August 6, 2011; accepted January 16, 2012; published online April 12, 2012

\begin{abstract}
We review and discuss some of the recent scientific findings made on magnetic data in the South China Sea (SCS). Magnetic anomalies bear extremely rich information on Mesozoic and Cenozoic tectonic evolution. 3D analytical signal amplitudes computed from magnetic anomalies reveal very precisely relict distributions of Mesozoic sedimentary sequences on the two conjugate continental margins, and they are also found very effective in depicting later-stage magmatism and tectonic transitions and zonation within the SCS oceanic crust. Through integrated analyses of magnetic, gravity and reflection seismic data, we define the continent-ocean boundary (COB) around the South China Sea continental margin, and find that the COB coincides very well with a transition zone from mostly positive to negative free-air gravity anomalies. This accurate outlining of the COB is critical for better tracing magnetic anomalies induced by the oceanic crust. The geometrically complex COB and inner magnetic zonation require the introduction of an episodic opening model, as well as a transform fault (here coined as Zhongnan Fault) between the East and Southwest Sub-basins, while within the East and Southwest Sub-basins, magnetic anomalies are rather continuous laterally, indicating nonexistence of large transform faults within these sub-basins. We enhance magnetic anomalies caused by the shallow basaltic layer via a band-pass filter, and recognize that the likely oldest magnetic anomaly near the northern continental margin is C12 according to the magnetic time scale CK95. Near the southern continental margin, magnetic anomalies are less recognizable and the anomaly $\mathrm{C} 12$ appears to be missing. These differences show an asymmetrical opening style with respect to the relict spreading center, and the northern part appears to have slightly faster spreading rates than to the south. The magnetic anomalies C8 (M1 and M2, 26 Ma) represent important magnetic boundaries within the oceanic basin, and are possibly related to changes in spreading rates and magmatic intensities. The magnetic evidence for a previously proposed ridge jump after the anomaly C7 is not clear. The age of the Southwest Sub-basin has yet to be further examined, most favorably with deep-tow magnetic surveys and ocean drilling. Our magnetic spectral study shows that the shallowest Curie points are located around the eastern part of the Southwestern Sub-basin, whereas within the East Sub-basin Curie depths are smaller to the north of the relict spreading center than to the south. This pattern of Curie depths is consistent to regional heat flow measurements and later-stage volcanic seamount distributions, and we therefore reason that Curie-depth variations are closely associated with later-stage magmatism, rather than with crustal ages. Although magnetic anomalies located around the northern continent-ocean transition zone (COT) are relatively quiet, this area is not a typical magnetic quiet zone since conceptually it differs markedly from an oceanic magnetic quiet zone. The relatively quiet magnetic anomalies are seemingly associated with a shallowing in Curie isotherm and thinning in magnetic layer, but our comprehensive observations suggest that the well-preserved thick Mesozoic sedimentary rocks are major causes for the magnetically quiet zone. The high similarities between various low-pass filtered marine and air-borne magnetic anomalies and satellite magnetic anomalies clearly confirm that deeper magnetic sources (in the lower crust and the uppermost mantle) have contributions to long-wavelength surface magnetic anomalies in the area, as already inferred from magnetically inversed Curie depths. The offshore south China magnetic anomaly (SCMA) becomes more prominent on low-pass filtered marine and air-borne magnetic anomalies and satellite magnetic anomalies, indicating very deeply-buried magnetic sources beneath it.
\end{abstract}

South China Sea magnetic anomalies, continent-ocean boundary, Zhongnan Fault, seafloor spreading, Curie-point depth, magnetic layer, filtering

Citation: $\quad$ Li C F, Song T R. Magnetic recording of the Cenozoic oceanic crustal accretion and evolution of the South China Sea basin. Chin Sci Bull, 2012, 57: 3165-3181, doi: 10.1007/s11434-012-5063-9

*Corresponding author (email: cfl@tongji.edu.cn) 
Of various types of geophysical data used in studying systematic evolution of the planet Earth, geomagnetic data may have recorded the most abundant and diverse information of the Earth's interior. In addition to contributing to traditional subjects like seafloor spreading and plate movement [1], lithosphere evolution and magmatism, characteristics of core rotation [2], and interactions between the Earth and outer space, geomagnetic data also play critical roles recently in our understanding of other geodynamic processes, such as global climate change [3], ocean tidal activities [4], mantle serpentinization and fluid flow [5,6], and geothermal field evolution [7]. In early investigations on the geodynamics of the South China Sea (SCS), magnetic anomalies were essential to determining the ages and stages of seafloor spreading [8-13], seamount magnetism, and directions of plate movement [14], but these early studies were based primarily on a very limited number of magnetic tracks that were often far spaced, thus leaving a large margin of uncertainties in estimated oceanic crustal ages and seamount magnetism. In recent years, with the publication of the East Asia Magnetic Anomaly Dataset [15], high-resolution magnetic anomaly maps in the SCS are compiled [16-19], and high-resolution 3D analytical signal amplitudes and
Curie point depths are calculated and mapped [17,20]. This magnetic anomaly dataset is based on measurements by multiple platforms at different time, with varying degrees of noise suppression, and no previous effort has been made in estimating the opening ages of the SCS based on this comprehensive database. However, this dataset is advantageous in that it is a compilation of magnetic tracks surveyed over many years and therefore has a very high track density (Figure 1). By taking advantage of this extremely high track density, we will be able to easily suppress both longwavelength background magnetic anomalies that are mostly due to deep sources and short-wavelength observational noises via 2D reinterpolation and denoising. Magnetic anomaly profiles so obtained should be more accurate than those often very sparsely and/or irregularly distributed profiles from any one single previous survey, thus paving a more sound foundation for further forward modeling and inversion of magnetic anomalies. This is the main idea of this study. The distribution of high-density magnetic lines made it possible to carry out $2 \mathrm{D}$ magnetic processing and inversion, through which we can infer regional tectonics and deep structures.

Through integrated processing and interpretation of

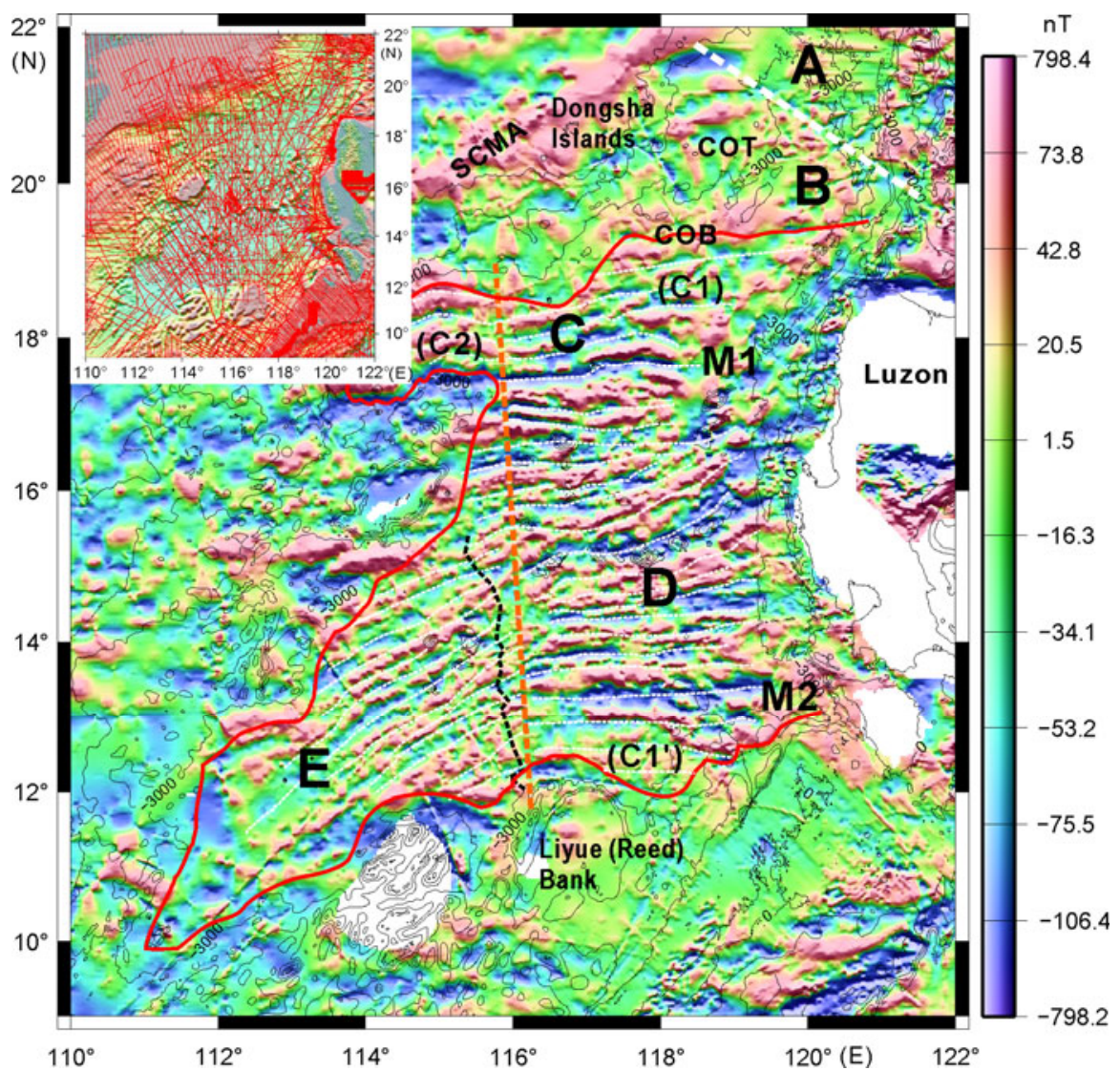

Figure 1 Total-field magnetic anomaly map of the South China Sea (SCS) showing magnetic zonation. A, B, C (C1, C1', C2), D, and E are different magnetic zones. M1 and M2 are major magnetic boundaries in the East Sub-basin, and their ages are estimated to be C8 ( 26 Ma). The red solid line marks the continent-ocean boundary (COB). The light yellow dashed line marks the Zhongnan Fault. The black dashed line marks the Zhongnan Ridge. The white bold dashed line marks the Luzon-Ryukyu Transform Boundary [12]. The white thin dashed lines are sketches of negative magnetic anomalies in the central basin. SCMA = offshore south China magnetic anomaly. The inlet in the upper left corner is the regional topography overlapped with magnetic tracks in red lines. 
magnetic (Figure 1), gravimetric (Figure 2), and reflection seismic data, we define the continent-ocean boundary (COB), estimate the ages of magnetic anomalies, and discuss the opening history of the SCS. With 2D magnetic processing and inversion, we estimate depths to the top and bottom, and thereby the thicknesses, of the magnetic layer. Furthermore, by analyzing various low-pass filtered marine and air-borne magnetic anomalies and their correlations to satellite magnetic anomalies, we make a preliminary discussion on key scientific questions such as cooling of the oceanic crust, and magnetization in the lower crust and uppermost mantle.

\section{Precise calibration and characterization of the continent-ocean boundary (COB)}

No consistencies have been reached on the precise delineation of the COB of the SCS. This is particularly true in the northern continent margin, where there are large controversies toward the nature of the continent-ocean transition zone (COT). Some have considered that the magnetic anomalies from seafloor spreading can be traced all the way northward to $21.5^{\circ} \mathrm{N}$, east of Dongsha Islands, and thereby argued that the initial opening of the SCS may not be later than $37 \mathrm{Ma}$
[12]. But in northeastern SCS there underlay well-developed Mesozoic strata, which contrasts sharply in seismic reflection characteristics to typical oceanic crust in the central SCS basin $[16,17]$. If there exists any oceanic crust in northeastern SCS, it might be only limited within the south depression of the Tainan Basin [16]. Therefore, possible oceanic crust here may be very limited in area, and is certainly different in nature from the oceanic crust in the central basin [16]. Similarly, in the southern continental margin of the SCS, different scientists also had markedly different views toward the COB [21]. Obviously, accurate outlining of the $\mathrm{COB}$ and understanding of its tectonic affiliation is the key to determining the incipient ages of seafloor spreading.

The accurate outlining of the $\mathrm{COB}$ requires integrated analyses of a variety of geophysical data. Here we comprehensively analyze magnetic, gravimetric and reflection seismic data, and find that the COB correlates very well to a transition zone in free-air gravity anomalies (Figure 2). Area floored with oceanic crust in the central basin corresponds mostly positive gravity anomalies, which are rimmed and surrounded by grossly negative gravity anomalies. The transition zone in between corresponds roughly with the COB.

This recognition of $\mathrm{COB}$ can be verified on reflection

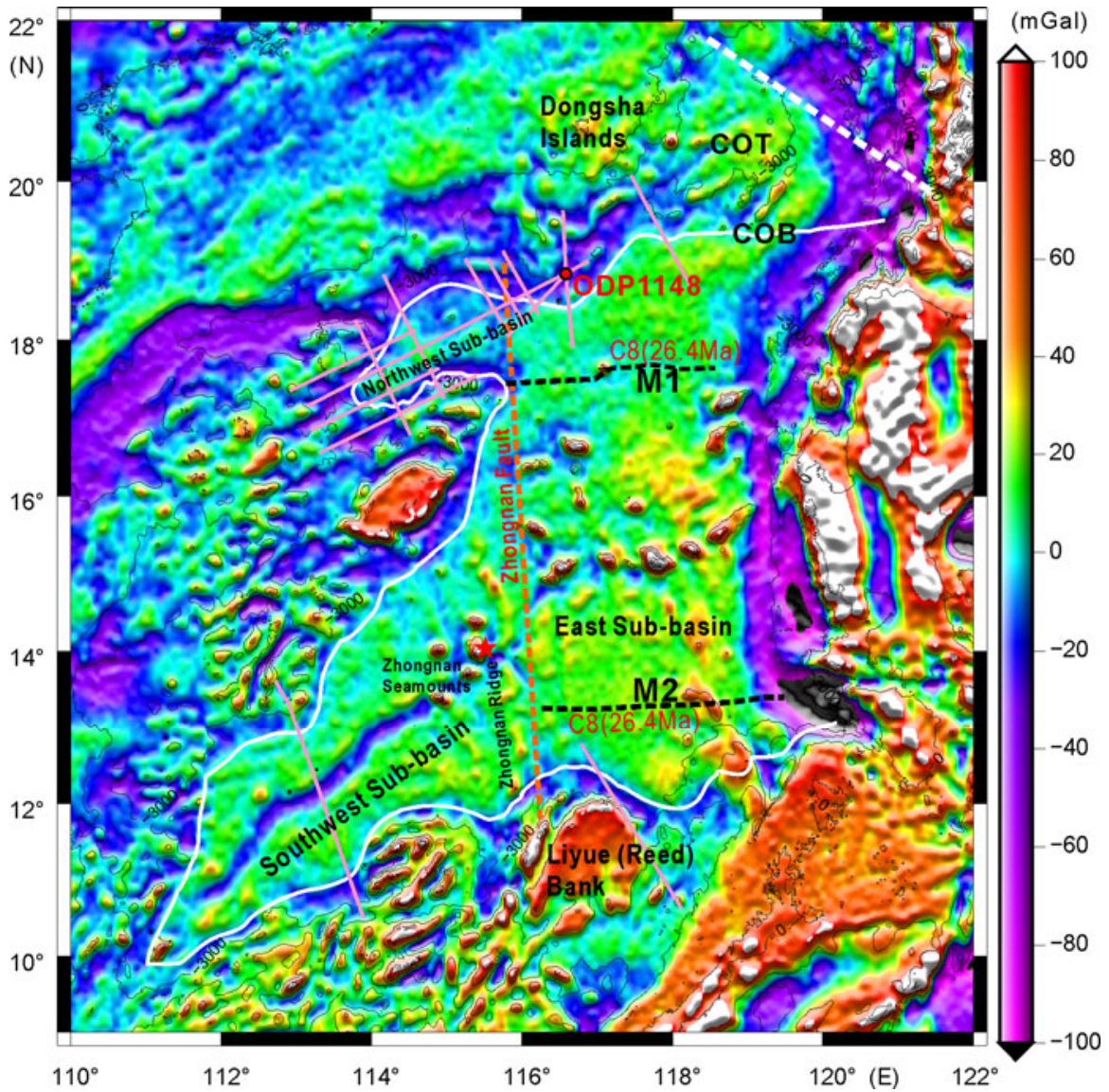

Figure 2 Free-air gravity anomaly map of the South China Sea (based on the 1-min grid). The light yellow solid lines are reflection seismic sections. The two bold black dashed lines mark the two magnetic anomalies M1 and M2 interpreted from Figure 1. The white solid line marks the interpreted COB. The red solid pentacle in the Zhongnan Seamounts marks the sampling site of alkaline basalts (K-Ar age: 3.49 Ma). See Figure 1 for other notations. 
seismic profiles. By correlating gravity anomalies with a number of seismic profiles crossing the COB, we have found that the COB revealed by seismic profiles coincides very well with the transition zone from mostly positive to negative free-air gravity anomalies. Therefore free-air gravity anomalies become essential to outlining the $\mathrm{COB}$ of the SCS. The positive free-air gravity anomalies over the oceanic crust are closely related to mantle uplift and high density of the oceanic crust, whereas in the transition zone, extension and subsidence of continental crust accompanied with draping of low-density sediments lead to overall negative free-air gravity anomalies.

As can be seen from the total-field magnetic anomaly map (Figure 1), the COB so determined encloses very well the area with clear seafloor spreading magnetic anomalies in the SCS. It would be difficult to determine the COB only based on the magnetic anomalies, because they become less continuous approaching the two conjugate continental margins, and the stripping features of magnetic anomalies become more blurred. The COB identified here shows a complex spatial pattern changing markedly along with the edges of the oceanic crust, and this not only reveals the complexity of incipient seafloor spreading, but also lends more difficulties to interpreting the onset ages of seafloor spreading in the SCS.

\section{Recognition of the magnetic zonation in the SCS}

Magnetic anomaly features differ markedly between different tectonic units of the SCS basin. Based on magnetic attributes like magnitudes, strikes, and frequencies, the SCS basin can be divided into five zones representing different crustal affiliations or oceanic crusts [17] (Figure 1). From detailed outlining of the $\mathrm{COB}$ mentioned above, we find that the $\mathrm{COB}$ crosses the magnetic zone $\mathrm{B}$ identified previously [17], so the area of zone B should be reduced, and its southern border should be defined by the COB. Correspondingly, zone $\mathrm{C}$ should be enlarged as zone $\mathrm{B}$ will be smaller, and zone $\mathrm{C}$ can be further subdivided along the Zhongnan Fault into zones $\mathrm{C} 1$ and $\mathrm{C} 2$, as differences in magnetic amplitudes and strikes across the Zhongnan Fault are also apparent (Figure 1). Zone C2 corresponds to the traditionally defined Northwest Sub-basin. The Northwest Sub-basin is previously known as a small residual oceanic basin died soon after its initial opening, and it has a relict spreading center, with which magnetic anomalies are nearly symmetrical. By contrast, there is not a relict ridge in zone C1 [8-10]. If so, the Zhongnan transform fault must be introduced in the northern SCS basin (Figure 1), in order to reconcile the differential spreading and movement caused by persistent spreading to its east in zone $\mathrm{C} 1$ after the spreading ceased to the west in zone $\mathrm{C} 2$.

The southern boundary of zone $\mathrm{C}$ is a conspicuous negative magnetic anomaly named M1. On the magnetic anom- aly map (Figure 1), M1 seems to extend to the southern margin of the Northwest Sub-basin. But from reflection seismic, gravimetric and bathymetric data, the negative magnetic anomaly bounding the Northwest Sub-basin to the south is located outside the oceanic crust enclosed by the $\mathrm{COB}$, but corresponds to seafloor magmatic activities developed in attenuated continental crust. One possible explanation is that these strong magmatic activities are coeval to seafloor spreading magmatism causing M1, so they bear similar magnetization characteristics. This indicates that the magnetic anomaly M1 corresponds to an important tectonic events in the seafloor spreading of the SCS. The magnetic anomaly M1 is previously identified as C8, and based on some geomagnetic polarity time scales it is dated as $\sim 27.5$ Ma [8-10]. Using the Talwani-type forward modeling, we estimate that the age of C8 is $\sim 26.4 \mathrm{Ma}$ based on the geomagnetic polarity time scale CK95 [1], and the age of C8 will be $\sim 26.0 \mathrm{Ma}$ if based on the new geomagnetic polarity time scale of Gradstein et al. [22]. These ages help attribute magnetic anomaly M1 to a magnetic reversal event in the middle late Oligocene. If the magmatic bodies located immediately south of the Northwest Sub-basin (magnetic zone C2) formed concurrently with seafloor spreading basalts causing the magnetic anomaly M1, we will be able to date the magnetic anomaly $\mathrm{C} 8$ by direct shallow drilling and coring into these magmatic bodies.

To the south of the relict spreading center in the East Sub-basin, the counterpart of M1 is M2 (Figure 1). Magnetic anomalies south of M2 are rather weak and the stripping feature is not obvious. But from seismic reflections and gravity anomalies, there still exists an area floored with oceanic crust, which should correspond to the magnetic zone $\mathrm{C} 1$ to the north given the approximate symmetry of seafloor spreading with the spreading center. So we name this area as zone $\mathrm{Cl}^{\prime}$. Obviously, zone $\mathrm{Cl}^{\prime}$ ' is smaller than zone $\mathrm{C} 1$ in size. This may indicate that the average spreading rate north of the spreading center was slightly larger than that to the south as the spreading center was moving southward. The same pattern is true within magnetic zone D confined by M1 and M2. Southward ridge jump may explain this phenomenon, but at least two jumps are needed to reasonably explain why the average seafloor spreading rates on both sides of M1 are always larger than their counterparts south of the relict spreading center. Yet with increasing number of jumps, each jump distance must be very short. Otherwise the scope of the oceanic crust north of the spreading center will be much larger than that to the south, and this contradicts our observations. Therefore it is unlikely that there are multiple ridge jumps to the east of the Zhongnan Fault. Early studies showed that a small ridge jump occurred after the magnetic anomaly C7 ( 27 Ma [10]), but based on the geomagnetic polarity time scale CK95 [1], the age of C7 is $24.8 \mathrm{Ma}$. From the total-field magnetic anomaly map (Figure 1), the major tectonic event within the oceanic crust east of the Zhongnan Fault may 
occurred near the magnetic anomaly C8 (M1/M2, $26.4 \mathrm{Ma})$ instead of after $\mathrm{C} 7$. This is because that magnetic anomalies after C8 are more visible with larger amplitudes. From seismic reflection profiles [20], it is seen that oceanic basement older than $\mathrm{C} 8$ is overall flat and is with thick overlying sediments, while that younger than $\mathrm{C} 8$ fluctuates heavily and has much shallower burials. We speculate that the tectonic event associated with $\mathrm{C} 8$ may not be caused by a ridge jump, but is more likely related to a change in spreading rates or magmatic magnitudes in the spreading center.

The stratigraphic records at the ODP Site 1148 drilled in 1999 in the SCS revealed a major tectonostratigraphic event around $25 \mathrm{Ma}$, forming an unconformity/slump zone with a 2-3 Ma of sedimentary hiatus and coincidental strong seismic reflections $[23,24]$. This event seems to coincide with a ridge jump ( 27 Ma [10]) after the magnetic anomaly $\mathrm{C} 7$, but evidences for a ridge jump after the $\mathrm{C} 7$ are not prevailing in the magnetic anomaly map (Figure 1). We tend to believe that the event revealed at the ODP Site 1148 was related to the formation of magnetic anomaly M1 (C8) and triggered by a change in seafloor spreading rate or midocean ridge magmatism. In the East China Sea, there also occurred strong regional compression, uplifting and erosion, and pervasive magmatic activities at the Oligocene-Miocene transition ( 23 Ma) [25]. Therefore this Oligocene-Miocene transitional tectonic event occurred throughout east China and caused regional instability.

\section{The Zhongnan Fault, Zhongnan Ridge and Zhongnan Seamounts}

Accurate delineations of tectonic boundaries within the SCS basin form the foundation to further calibrating the opening ages and episode of the SCS. There developed many interesting structures in the transition zone between the East and Southwest Sub-basins. From west to east, they are the Zhongnan Fault, Zhongnan Ridge, and Zhongnan Seamounts, respectively (Figures 1 and 2). About the Zhongnan Fault, previous studies have already suggested for its existence as a transitional boundary [8,9], which played a central role in the multi-stage opening models of the SCS $[11,16,26]$. Despite existing specific investigations on the Zhongnan Fault [27], there still remain different views on the exact strike and location of the fault. As mentioned above, in order to reconcile the markedly different magnetic anomalies and differential movement between the Northwest Sub-basin (magnetic zone C2) and East Sub-basin (magnetic zone $\mathrm{C} 1$ ), a transform fault should be introduced. We find that this proposed transform fault can be connected to the south with the transform fault between the East and Southwest Sub-basins, forming a large regional transform fault (Figure 1). From detailed analyses of magnetic anomalies, we find that across the Zhongnan Fault there are large differences not only in magnetic strikes but also in magnetic intensities and magnetic layer structures [17,20]. The Zhongnan Fault demonstrates itself clearly on seismic profiles [17]. It also shows up as a zone of low free-air gravity anomalies on Figure 2 and as a low depression on the topography map (Figure 3 ).

The Zhongnan Ridge is located west of, and is subparallel to, the Zhongnan Fault (Figures 1-3). It appears overall as a beaded and jagged low upheaval. It has a V-shaped apex on seismic sections [8,9], and its internal seismic reflections show evidences of strong deformation, due likely to compression along a pre-existing fracture zone. As the overlying sediments on the ridge are very thin, oceanic basement may be directly exposed at the seabed. Crustal fluid flow could be very strong here, and this makes it a potential site to verify whether there are fluids coming directly from the mantle and whether there is in-situ mantle serpentinization. On the magnetic anomaly map (Figure1), the Zhongnan Ridge seems to be correlated with weak magnetic anomalies, but further analyses in this aspect await high-resolution deep-towed magnetic surveys. If this correlation indeed exists, it implies that the formation of the ridge is accompanied with demagnetization in oceanic crustal basalts. On the free-air gravity anomaly map, the Zhongnan Ridge is clearly associated with high gravity anomalies (Figure 2).

The Zhongnan Seamounts are located in the eastern part of the Southwest Sub-basin and to the west of the Zhongnan Ridge (Figures 1-3). We can see five isolated seamounts from the gravity anomaly map. Three of them developed roughly along the relict spreading center, and the other two are located to the north of the spreading center. Geochemical dating on seamounts in the SCS shows a southward younging in their ages from the northern continental margin to the relict spreading center [28]. One K-Ar dating on the alkaline basalt sample from the Zhongnan Seamounts gives an age of $3.49 \mathrm{Ma}$ (Figure 2), and the ${ }^{87} \mathrm{Sr} /{ }^{86} \mathrm{Sr}$ ratio indicates that the magma are from upper mantle differentiation and partial melting [28]. From magnetic data inversion, $\mathrm{Cu}-$ rie-point depths and depths to top of the magnetic layer are found anomalously small in the Southwest Sub-basin, particularly near the Zhongnan Seamounts. These shallow depths and their good correlations to very young magmatism of the Zhongnan Seamounts all support that there are anomalously strong post-spreading geothermal and magmatic activities in the Southwest Sub-basin. Therefore, the anomalously higher surface heat flow in the Southwest Sub-basin than in the East Sub-basin is possibly linked to stronger late-stage magmatism there and may not be used directly in inferring the ages of the oceanic crust.

\section{Revisiting the opening episodes of the SCS basin}

High-density magnetic measurements are fundamental to 


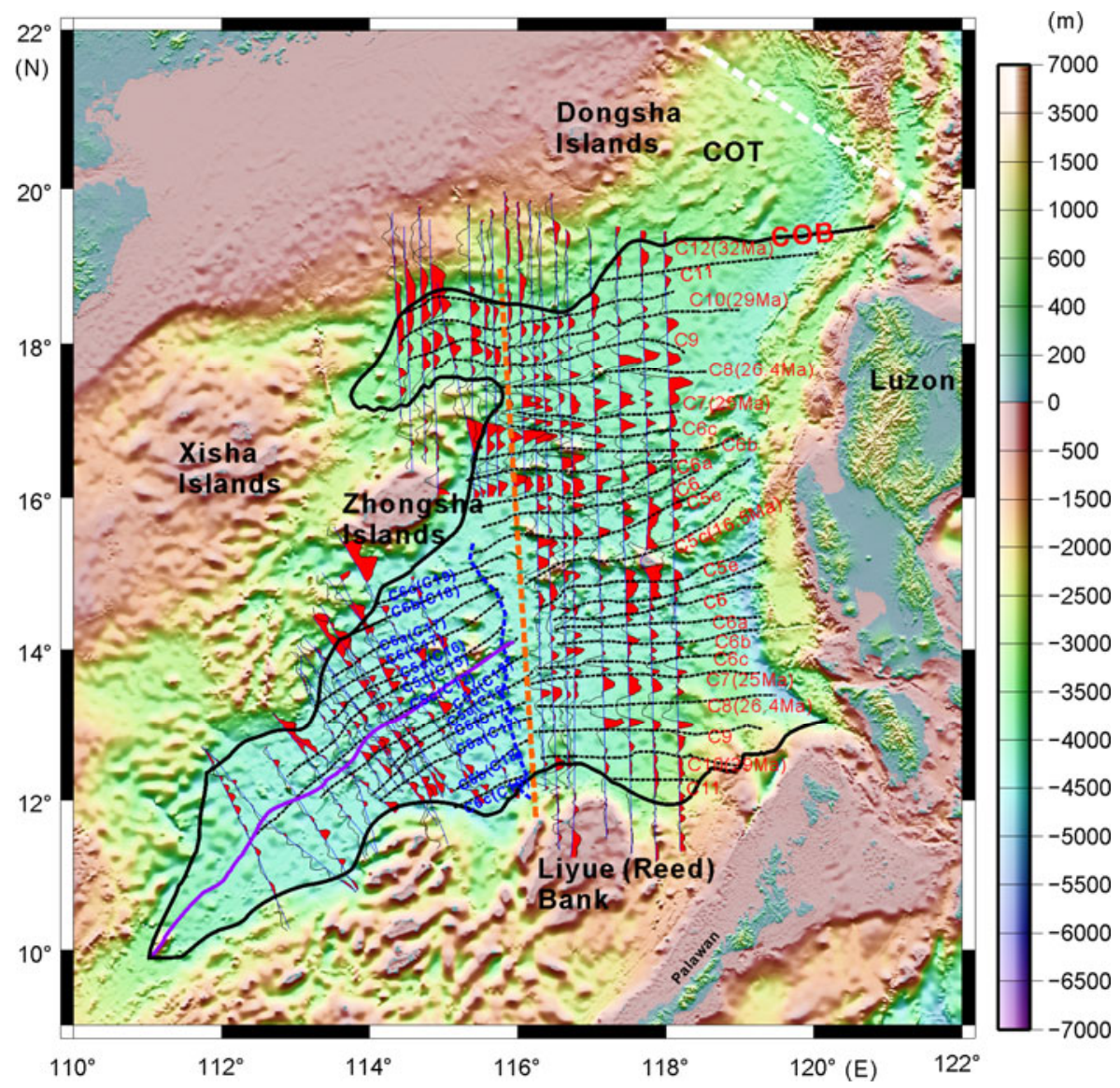

Figure 3 Bathymetry, key magnetic profiles, and interpreted ages and their spatial distributions [29]. The black thin dashed lines are sketches of interpreted negative magnetic anomalies in the central basin. Their preliminary ages are modeled based on the geomagnetic polarity time scales CK95 [1]. Two possible but different seafloor spreading models are shown in the Southwest Sub-basin. The purple solid line in the Southwest Sub- basin shows the track of the negative free-air gravity anomaly along the relict spreading center (Figure 2). See Figure 1 for other notations.

detailed outlining of magnetic anomalies. Here we choose magnetic anomalies from key profiles and display them on the bathymetric map (Figure 3). Meanwhile, we trace major negative magnetic anomalies on the total-field magnetic anomaly map (Figure 1) and draw them on Figure 3 as well. It can be seen that magnetic anomalies are rather continuous and can be well traced in both the Southwest and Eastern Sub-basins. This supports our argument that there are no big transforms faults within these two sub-basins.

The total-field magnetic anomaly map (Figure 1) contains both high-frequency noise and low-frequency background anomalies produced mostly by magnetic sources within deep crust and uppermost mantle [20]. These signal components need to be filtered out in order to enhance the magnetic anomalies caused mainly by the upper basalt layer (layer 2A) from seafloor spreading. Here with a 2D wavelength-domain cosine-tapered band-pass filter, we cut all wavelength components longer than $200 \mathrm{~km}$ and shorter than $10 \mathrm{~km}$, and pass all wavelength components between $20 \mathrm{~km}$ and $100 \mathrm{~km}$. Wavelengths in between will be cosine-tapered (Figure 4) with this filter. We find, by comparing Figure 1 and Figure 4, that the filtered magnetic anoma- lies turn to be more easily recognizable, especially in the Southwest and Northwest Sub-basins. Before filtering, there are large long-wavelength magnetic anomalies in the Northwest Sub-basin and its environs, which to a certain extent have disguised magnetic anomalies from seafloor spreading. After the filtering, the original low-frequency anomalies are drastically reduced, and anomalies caused by seafloor spreading can be easily recognized (Figure 4). The new magnetic dataset shown in Figure 4 is our basis of additional forward magnetic modeling in dating the seafloor spreading ages of the SCS basin [29].

We performed forward modeling on magnetic anomalies along selected key 2D profiles within the East and Southwest Sub-basins based on the software MODMAG [30] and geomagnetic polarity time scale CK95 [1]. After comparing calculated with observed magnetic anomalies, and correlating between different profiles and between different subbasins, we estimate the opening ages of the SCS [29]. Despite the overall fuzziness of older magnetic anomalies formed near the $\mathrm{COB}$, we find that the oldest magnetic anomaly near the northern SCS continental margin can be C12 ( 32 Ma), while near the southern margin the existence 


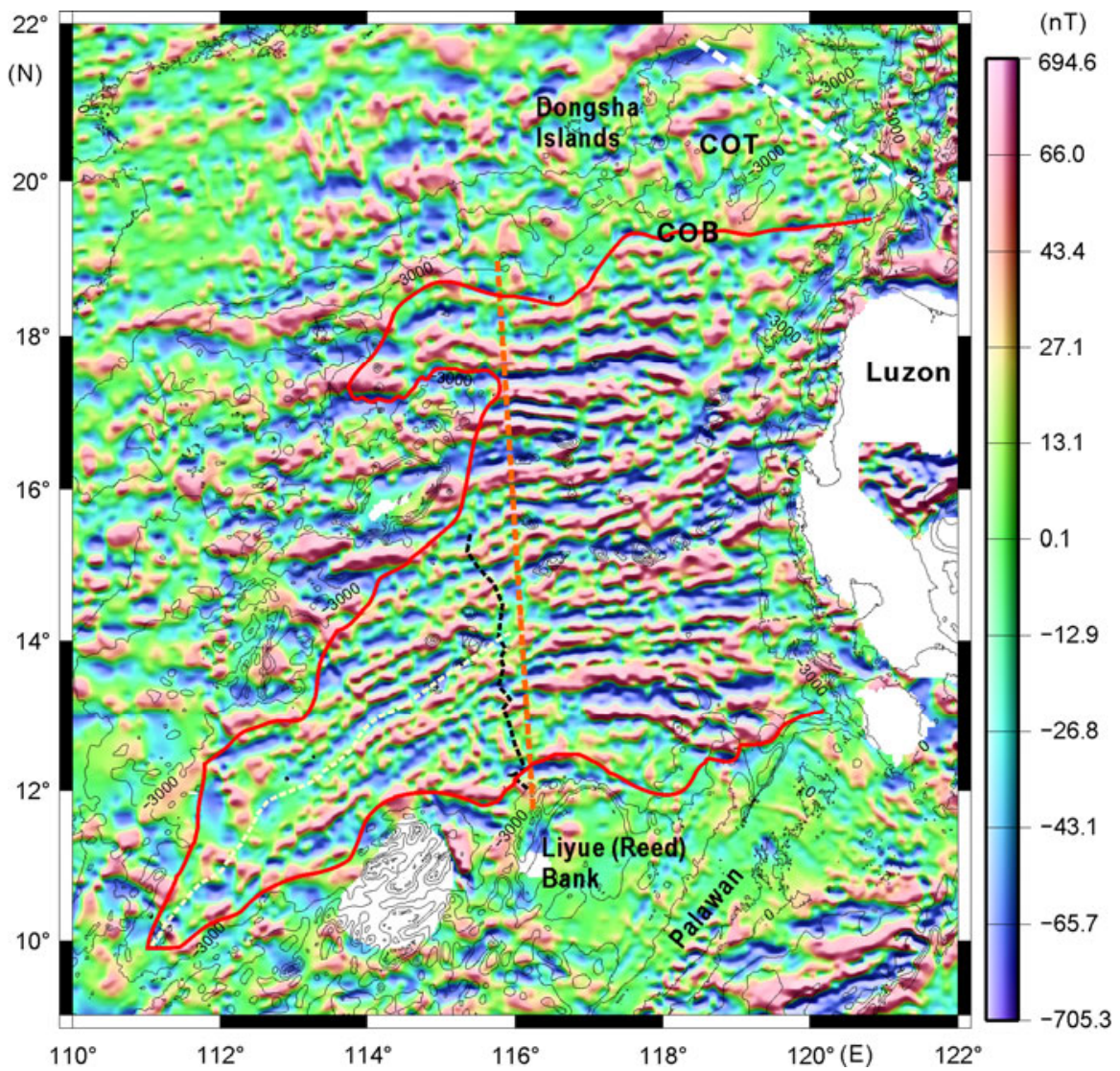

Figure 4 Total-field magnetic anomaly map of the South China Sea after the 2D wavenumber-domain filtering. The light yellow dashed line in the Southwest Sub-basin shows the track of the negative free-air gravity anomaly along the relict spreading center (Figure 2). See Figure 1 for other notations.

of C12 is dubious (Figures 3 and 4). As the original size of the SCS before its subduction along the Manila Trench should be much larger, we cannot exclude the possible existence of even older oceanic crust, which might have already been subducted today. For the Southwest Sub-basin, there still remain large uncertainties in its possible opening ages. We find that modeled magnetic anomalies from two different age models can all fit reasonably well with observed anomalies [29] (Figure 3), although different age models are accompanied with different spreading rates in the modeling. Due to these ambiguities, it remains rather difficult to determine whether the Southwest and East Subbasins opened in a sequential order or simultaneously. The noticeable tectonic and geophysical differences (Table 1) across the Zhongnan Fault can hardly be explained by a single-episode opening model. In the East Sub-basin, the spreading direction changed slightly from $\mathrm{S}-\mathrm{N}$ into NNWSSE after the magnetic anomaly C6a ( 21 Ma), whereas the spreading direction of the Southwest Sub-basin remained to be NW-SE throughout its history (Figures 3 and 4). Before an actual implementation of ocean drilling into the oceanic crust, accurate dating of the oceanic crust requires the

Table 1 Tectonic and geophysical differences between the East and Southwest Sub-basins

\begin{tabular}{lcc}
\hline \multicolumn{1}{c}{ Attributes } & East Sub-basin & Southwest Sub-basin \\
\hline Water depths & shallower on average & deeper on average \\
Basement depths & close (deepen to the margins) & ldeepen to the west) \\
Heat flow & lower & east-west \\
Magnetic strikes & stronger & preferentially high in high-wavenumber components \\
Magnetic amplitudes & preferentially low in high-wavenumber components & lower \\
Magnetic spectra & higher & mostly smaller \\
Free-air gravity anomalies & mostly larger & stronger \\
Curie depths & weaker &
\end{tabular}


incorporation of comprehensive analyses of Cenozoic tectonic unconformities within the rifting basins developed on the two conjugate continental margins of the SCS.

\section{Deep magnetic layer structure and thermal evolution}

Our present knowledge of deep structures beneath the SCS basin come primarily from surface wave tomography [31], the results of which, however, are of low resolutions. Deep high-resolution 2D and 3D seismic imaging by means of ocean bottom seismometers (OBS) has just begun in the north continental margin and oceanic basin [32]. The highdensity magnetic grid provides an alternative effective solution to picking up high-resolution deep geological structures. Existing studies on the magnetic structures of the SCS basin include the following: (1) Nonhomogeneous magnetic inversions of seamounts reveal large differences in plate motion and ages between the east and southwest parts of the SCS basin [14,33]; (2) interpolation-cut analyses of magnetic anomalies indicate that most magnetic sources are within $5 \mathrm{~km}$ in depths in the Southwest Sub-basin, but in the East Sub-basin deeper magnetic sources also contributed largely to surface magnetic anomalies [34]; (3) inversions of magnetic sources in deep basements are achieved by lowlatitude reduction to the pole and wavelet-based multiscale analyses [18]; (4) 3D analytic signal amplitudes are calculated and are used in detecting depths to the tops of magnetic sources [17]; and (5) high-resolution estimation of Curie-point depths is achieved for the SCS region [20].

Through calculating amplitude spectra of total-field magnetic anomalies within various window sizes, we obtained regional Curie-point (also known as Curie isotherm or bottom of the magnetic layer) depths and depths to the top of the magnetic layer at relatively high resolutions [20]. There are slight differences in fine details of Curie depths calculated from using different window sizes. In order to better show the variations in regional Curie isotherm, we take the average of Curie depths estimated using three different window sizes in $144.15 \mathrm{~km} \times 144.15 \mathrm{~km}, 99.2 \mathrm{~km}$ $\times 99.2 \mathrm{~km}$, and $68.2 \mathrm{~km} \times 99.2 \mathrm{~km}$, respectively (Figure 5). It is found that the eastern part of the Southwest Sub-basin has the smallest Curie depths, which may be related to strong late-stage magmatic activities. In the East Sub-basin, we find that Curie depths are smaller to the north than to the south of the relict spreading center, implying that deep geothermal activities are more vigorous to the north. These

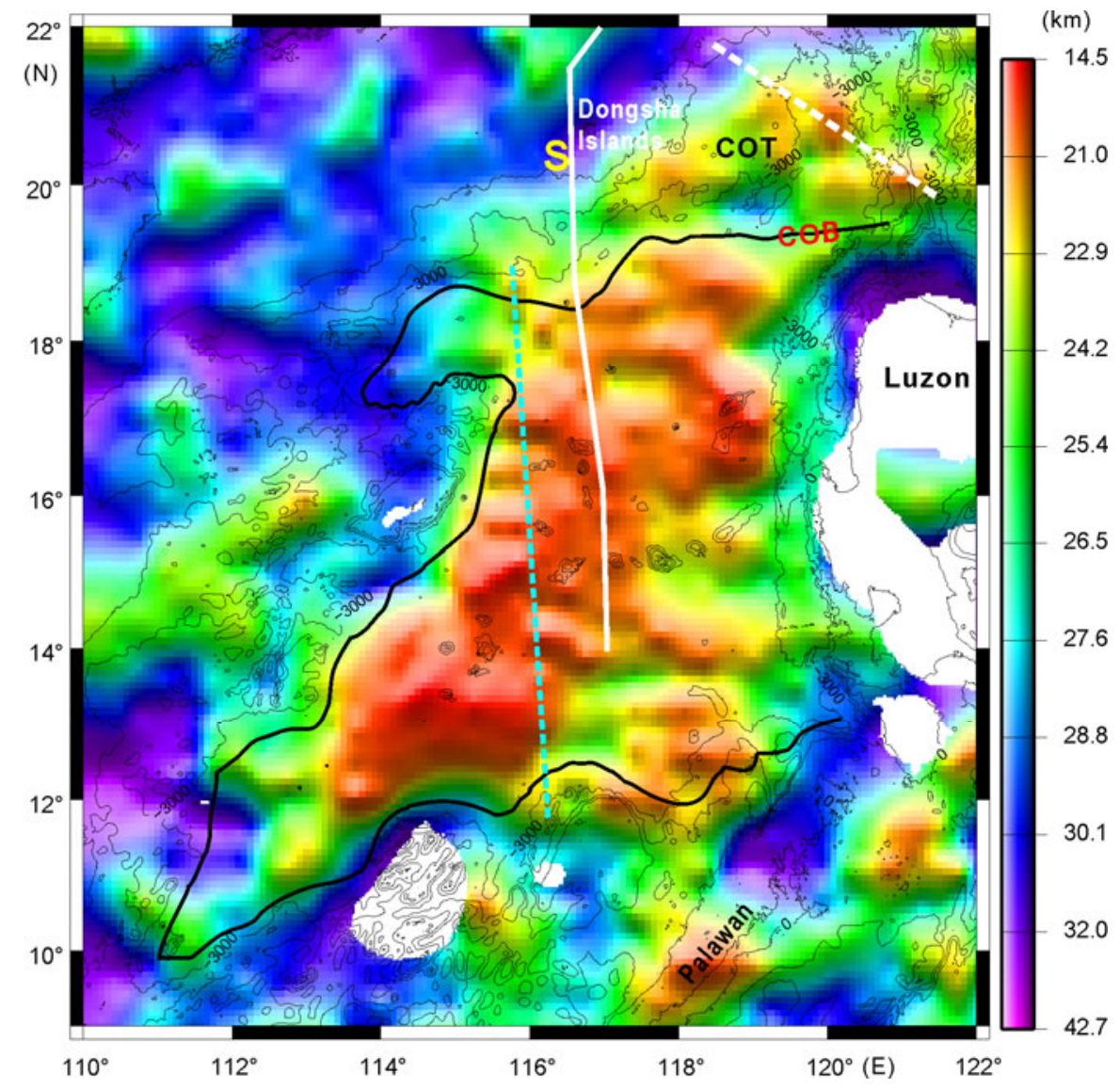

Figure 5 Map of Curie-point depths estimated from magnetic anomalies of the SCS assuming random 2D magnetization models. The white line marks the position of the reflection seismic line shown in Figure 8. COT: Continent-ocean transition zone. See Figure 1 for other notations. 
observations are conformable with late-stage magmatic activities in the East Sub-basin, which are also stronger to the north than to the south of the relict spreading center (Figures 2 and 3). One possible explanation is that the gradual southward migration of the spreading center left more intense residual thermal activities in the deep mantle to the north. The Curie depths are also relatively smaller within the COT of the northern SCS margin, again consistent with stronger deep magmatic activities there. In the Northwest Sub-basin and the southwest corner of the Southwest Sub-basin, Curie depths are relatively large, perhaps due to rapid cooling of narrow oceanic basins.

Our method can simultaneously estimate depths to the top of the magnetic layer. Figure 6 shows the average of these depths calculated from using three different window sizes in $144.15 \mathrm{~km} \times 144.15 \mathrm{~km}, 99.2 \mathrm{~km} \times 99.2 \mathrm{~km}$, and $68.2 \mathrm{~km} \times 99.2 \mathrm{~km}$, respectively. Top of the magnetic layer is very shallow in the northern SCS continental margin, particularly around the Dongsha area. This is consistent with observations from reflection seismic data. Depths to the top of the magnetic layer are averaged at $\sim 4.5 \mathrm{~km}$ in the central basin, also a value conformable with known bathymetry and sedimentary thicknesses. Interestingly, most seamounts do not coincide with shallow depths to the top of the magnetic layer. This is likely caused by the fact that our method cannot detect locally small and isolated features. Another possibility is that the seamounts formed from multiple episodes of volcanic eruptions and consequently they do not preserve outstanding magnetic patterns due to variable internal magnetizations of volcanic rocks. An obvious exception to this is the Zhongnan Seamounts, showing very shallow depths to the top of the magnetic layer, which possibly reflect strong late-stage magmatism as supported by a known young K-Ar age of sampled basalt here.

By subtracting depths to the top from depths to the bottom (Curie depths), we compute the thicknesses of the magnetic layer (Figure 7), which are found mostly between 15 and $30 \mathrm{~km}$. These thicknesses in the central SCS basin where oceanic crust developed and in the COT of the northern SCS margin (mostly smaller than $23 \mathrm{~km}$ ) are clearly smaller than those of the surrounding areas (mostly larger than $23 \mathrm{~km}$ ). Since the thicknesses of the oceanic crust in the central basin are mostly smaller than $10 \mathrm{~km}[20,35]$, there possibly exists a magnetized layer of about $10 \mathrm{~km}$ in thickness in the uppermost mantle of the SCS, which can contribute to surface magnetic anomalies. The uppermost

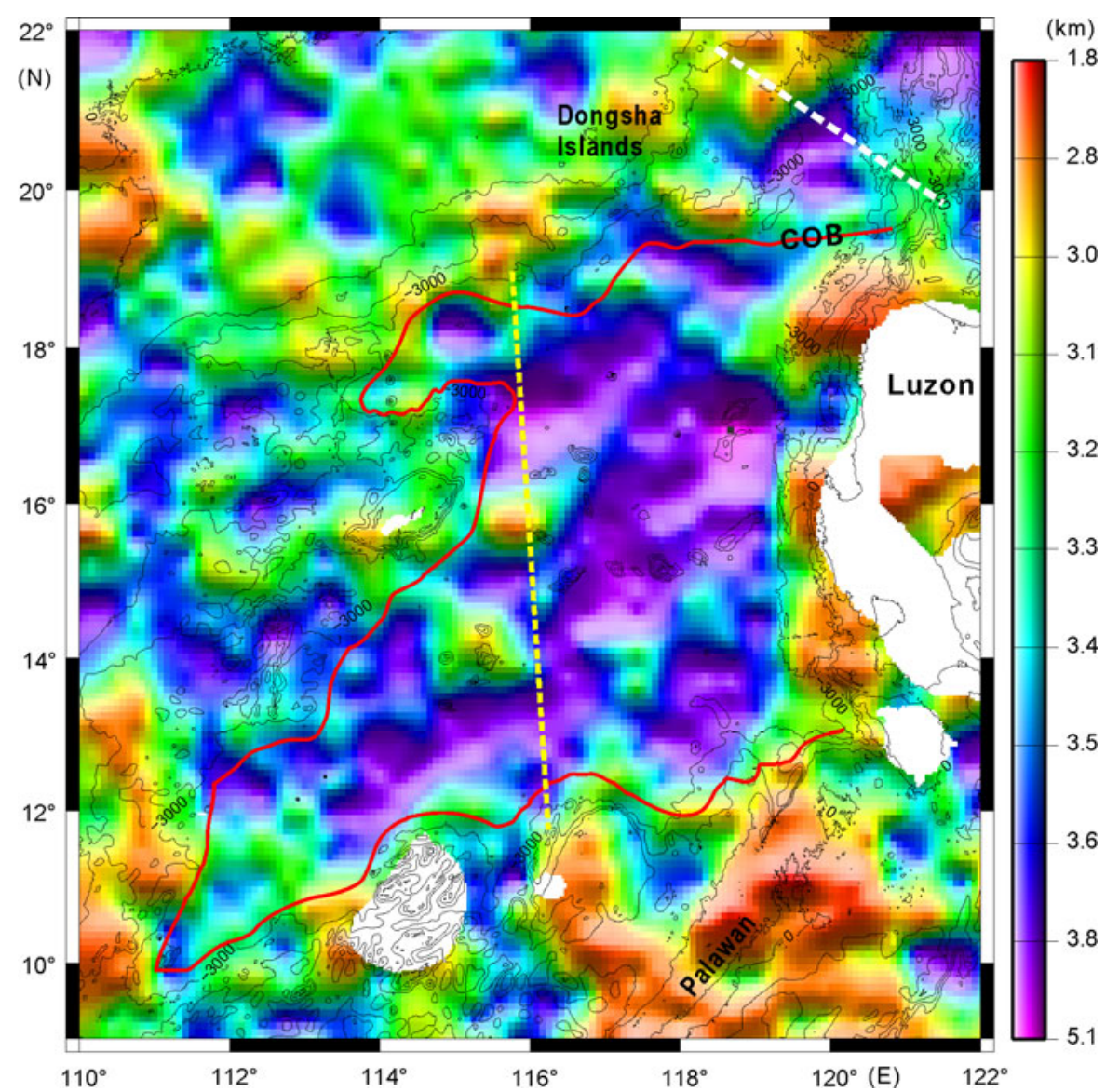

Figure 6 Map of depths to the top of the magnetic layer estimated from magnetic anomalies of the SCS assuming random 2D magnetization models. See Figure 1 for other notations. 


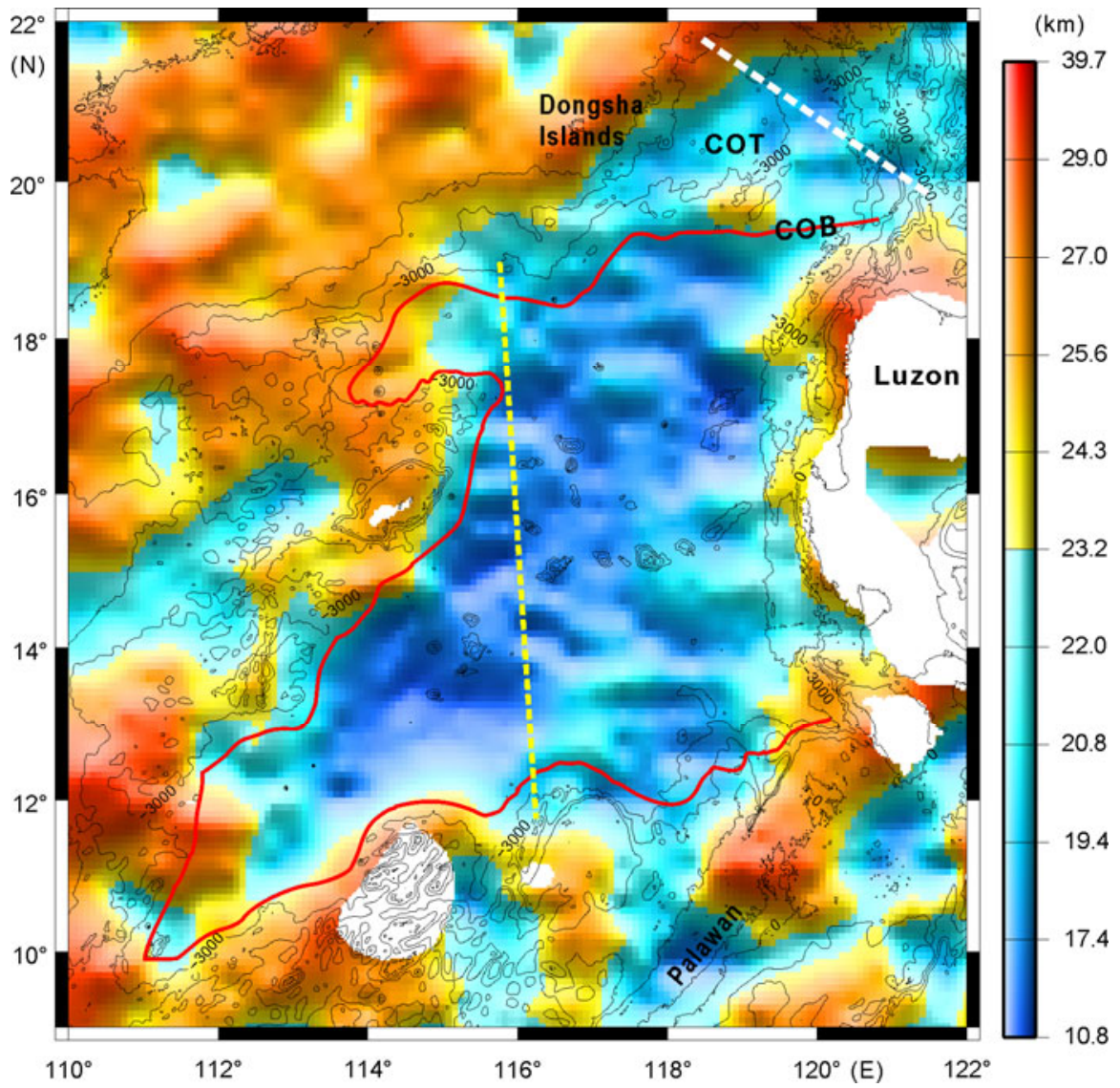

Figure 7 Map of thicknesses of the magnetic layer estimated from magnetic anomalies of the SCS assuming random 2D magnetization models. COT: Continent-ocean transition zone. See Figure 1 for other notations.

mantle beneath the COT and the offshore south China magnetic anomaly (SCMA) could also be magnetized (Figure 8). Deep seismic profiling found high-velocity layer caused by underplating in the lower crust beneath the COT of the northeast SCS continental margin [36,37]. Further investigations are needed to examine if the lower crust and upper mantle magnetization here are connected to the underplating. Likewise, it remains to be an open question on the mechanisms of lower crust and upper mantle magnetization as well as their contribution to surface magnetic anomalies [38]. In fact, these types of questions and arguments have existed ever since the early buildup of the Vine-Matthews model [39-45]. Earlier, magnetic sources causing seafloor spreading magnetic anomalies are thought to be confined within the shallow part of the oceanic crust, but satellite magnetic anomalies and ODP drilling confirm that these magnetic sources can be deep seated, and the gabbro layer of the lower crust can also contribute appreciably to surface magnetic anomalies. These new findings have raised questions on how oceanic crusts really formed [46,47]. Satellite magnetic measurements capture long wavelength magnetic anomalies, and thus are better suited for studying longwavelength magnetic variations and their deep sources. Complementarily, near-bottom high-resolution magnetic surveys that are being planned in the SCS will be able to measure short-wavelength magnetic anomalies, thus greatly increasing our precisions, scales and resolutions in observing short-period magnetic polarity reversals, excursions and paleo-intensity variations. Altogether, these data will better reveal the structures of the magnetic layer at various scales $[2,6,48-51]$.

To better understand the mechanisms of magnetizations in deep crust and upper mantle and their affects on nearsurface magnetic anomalies, we apply low-pass filtering to enhance long-wavelength anomalies induced by deep magnetic sources. Figure 9 shows the results from using various low-pass filters. The result from convolving in the space domain a Gaussian filter of $200 \mathrm{~km}$ wide with the magnetic anomalies of the SCS (Figure 9) shows that, near the COT (including the northern part of the Northwest Sub-basin) in the northern SCS continental margin, there are strong long-wavelength magnetic anomalies, which are likely caused by magnetizations of the uppermost mantle and lower crust. The E-W striking magnetic anomalies in the East Sub-basin are still visible, and so are the differences in magnetic patterns between the East and the Southwest Sub-basins. Furthermore, we use low-pass filters of a series of different cutoff wavelengths to progressively remove short-wavelength and enhance long-wavelength anomalies (Figure 9(b)-(d)). We find that magnetic anomalies from 


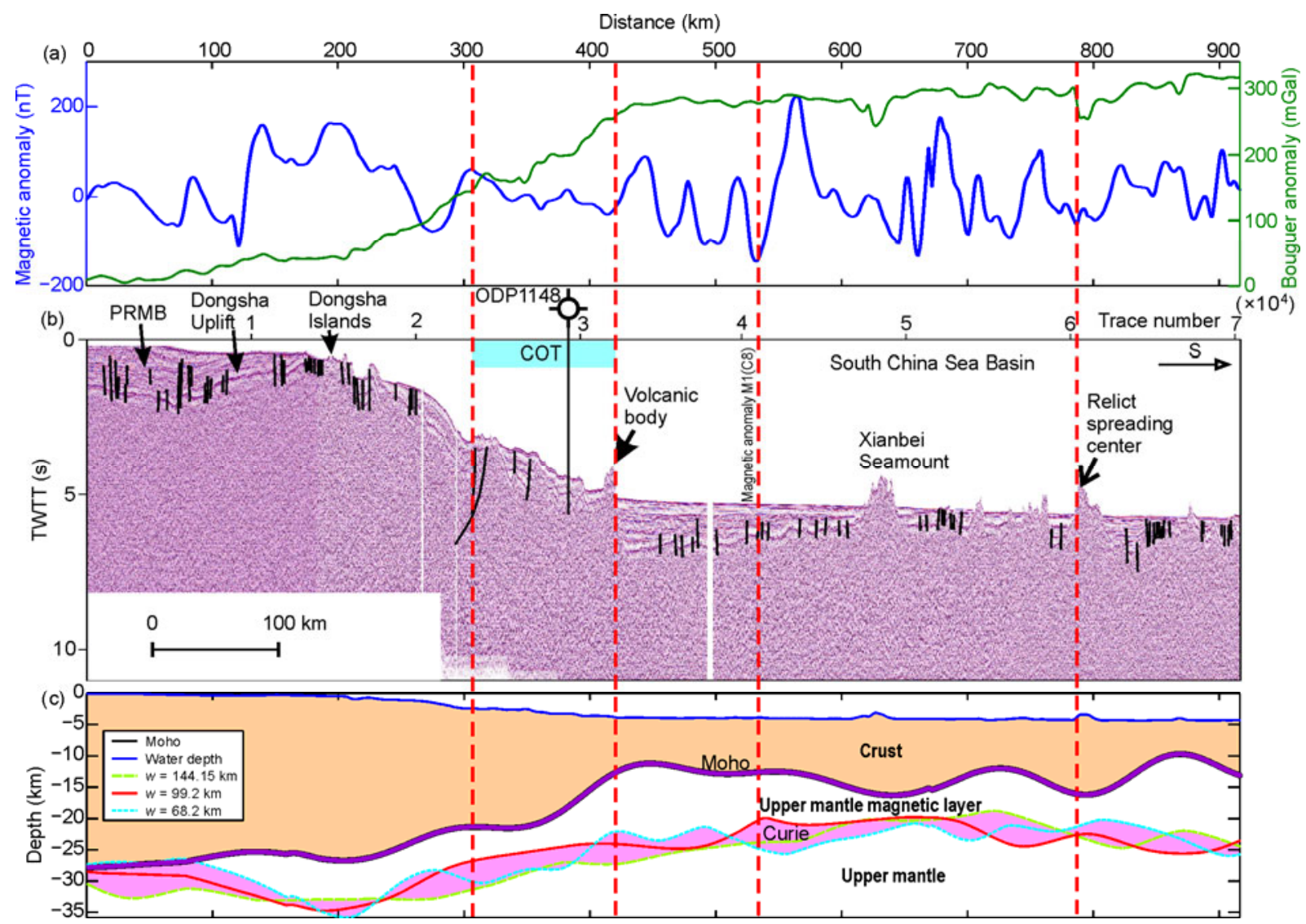

Figure 8 A regional geophysical profile in the SCS revealing magmatic activities, relationships between Curie and Moho depths, and key magnetic boundaries [20]. It is seen clearly from this map that the magnetic quiet zone in the northern SCS continental margin coincides roughly to the COT there. TWTT: Two-way travel time.

the shallow basaltic layer from seafloor spreading are no longer obvious after taking the low-pass filtering with a 200 $\mathrm{km}$ cutoff wavelength (Figure 9(b)). After the low-pass filtering with a $300 \mathrm{~km}$ cutoff wavelength (Figure 9(b)), there are still strong positive magnetic anomalies in the northern part of the East Sub-basin and the eastern part of the Southwest Sub-basin, which are possibly genetically connected to shallow Curie points and thick magnetic layers in these places. The magnetic anomalies in the northern part of the Northeast Sub-basin started to connect with the SCAM. Using a low-pass filter with a $400 \mathrm{~km}$ cutoff wavelength (Figure 9(b)), we can still see strong positive magnetic anomalies in the northern part of the East Sub-basin and the eastern part of the Southwest Sub-basin, and the SCMA becomes more outstanding. Other major magnetic anomalies also strike in NE-SW. All these filtering results indicate that the magnetic sources inducing the SCMA are deeply buried. This conclusion is consistent to interpretations from reflection seismic data near the SCMA, which show very well preserved Mesozoic strata at shallow depths [17].

Afore-mentioned processing and interpretation all utilized regional air-borne and marine magnetic anomalies, which are less capable of capturing long-wavelength magnetic anomalies due to their limited survey sizes. To further verify the existence of long-wavelength components in regional air-borne and marine magnetic anomalies, we make a regional map of satellite magnetic anomalies (Figure 10) of the same area as in other figures using the newly derived crustal and upper mantle magnetic field model MF7 (http:// geomag.org/models/MF7.html) that was produced using CHAMP measurements from May 2007 to April 2010 (http:// www-app2.gfz-potsdam.de/pb1/op/champ/). From comparisons, we find that the regional air-borne and marine magnetic anomalies low-pass filtered using $300 \mathrm{~km}$ and $400 \mathrm{~km}$ cutoff wavelengths (Figure 9(c),(d)) bear high similarities to the regional satellite magnetic anomalies (Figure 10), both in magnetic strikes and anomaly distributions. This observation supports that our processed air-borne and marine magnetic anomalies (Figure 9(c),(d)) do contain true regional long-wavelength magnetic anomalies contributed mainly by lower crust and upper mantle magnetic sources, and also verifies our computed results of Curie-point depths.

\section{Discussions on the magnetic quiet zone in the northern SCS continental margin}

In recent years, the magnetic quiet zone in the northern SCS 

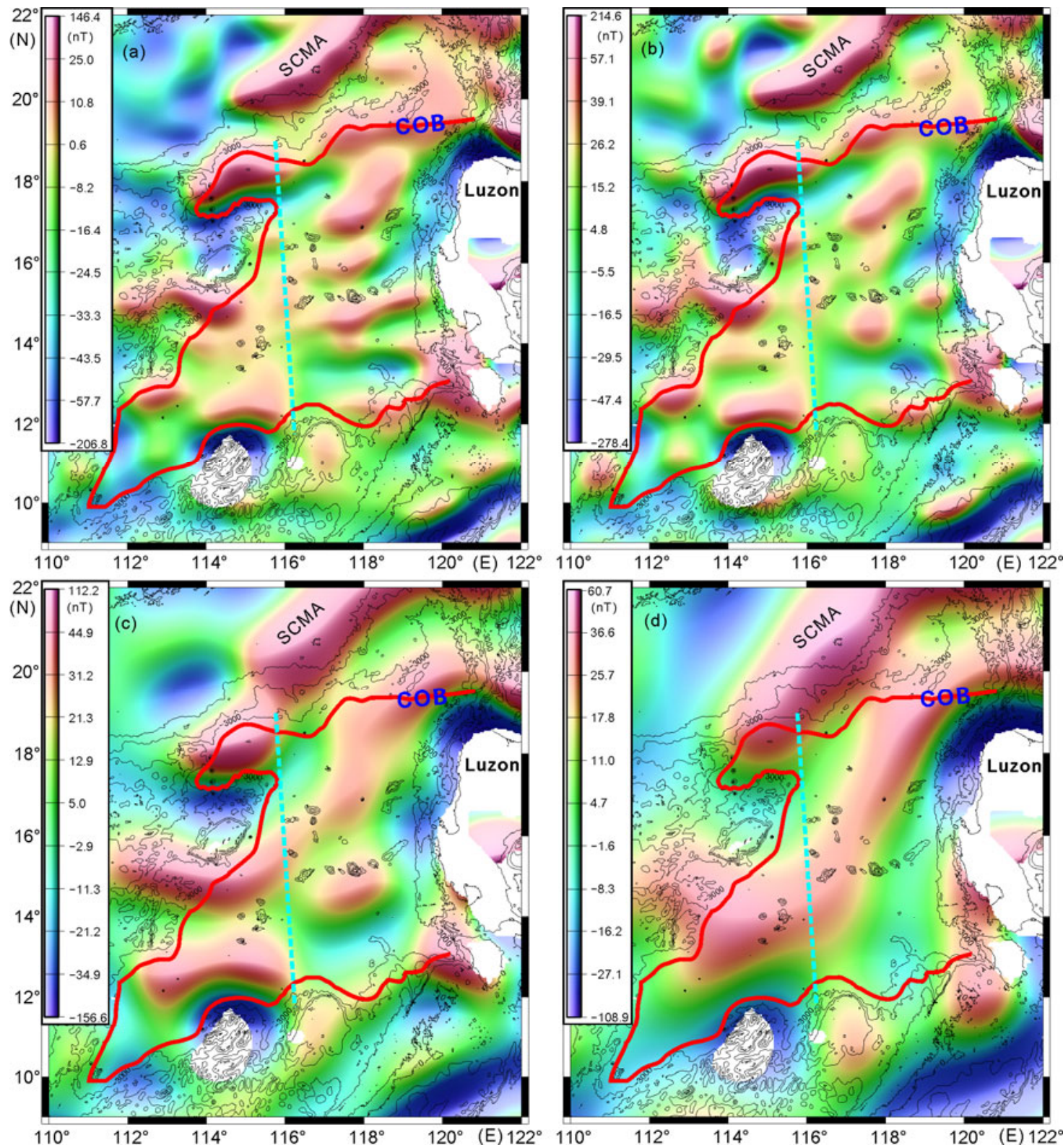

Figure 9 Maps of long-wavelength magnetic anomalies after filtering with 4 types of low-pass filters. (a) Using a Gaussian filter of $200 \mathrm{~km}$ wide in the space domain; (b) using a low-pass filter with a $200 \mathrm{~km}$ cutoff wavelength; (c) using a low-pass filter with a $300 \mathrm{~km}$ cutoff wavelength; (d) using a low-pass filter with a $400 \mathrm{~km}$ cutoff wavelength. See Figure 1 for other notations.

continental margin (Figure 1) has attracted the attention of many scientists. They have applied different techniques in processing and analyzing the magnetic anomalies $[17,20$, 52-56], and examined depths to the magnetic basement and causes of the magnetic quiet zone and lower crustal highvelocity layer. Some consider its unique geodynamic background being located in the COT of the northern SCS continental margin, where high-temperature mantle materials upwelled and emplaced as dikes into tectonically weak zones, causing elevated Curie isotherms and thinned magnetic layer, and consequently forming the magnetic quiet zone by demagnetization [52]. It indeed looks that the Curie points are elevated (Figure 5) and the magnetic layer is thinned in the COT (Figure 7), however, there are presently no strong evidences supporting that thinning in the magnetic layer will weaken magnetic anomalies, unless accompanied with intense hydrothermal activities and demagnetization of basalts.

The concept of the magnetic quiet zone was originally brought out from the studies in the Atlantic, and is used in referring magnetic quiet areas within oceanic crusts that distinguish themselves sharply from typical oceanic crusts of strong magnetic anomalies induced from seafloor spreading and magnetic reversals of the Earth [57]. In early studies of magnetic anomalies in the northern SCS continental margin, scientists also indicated that there is a magnetic quiet 


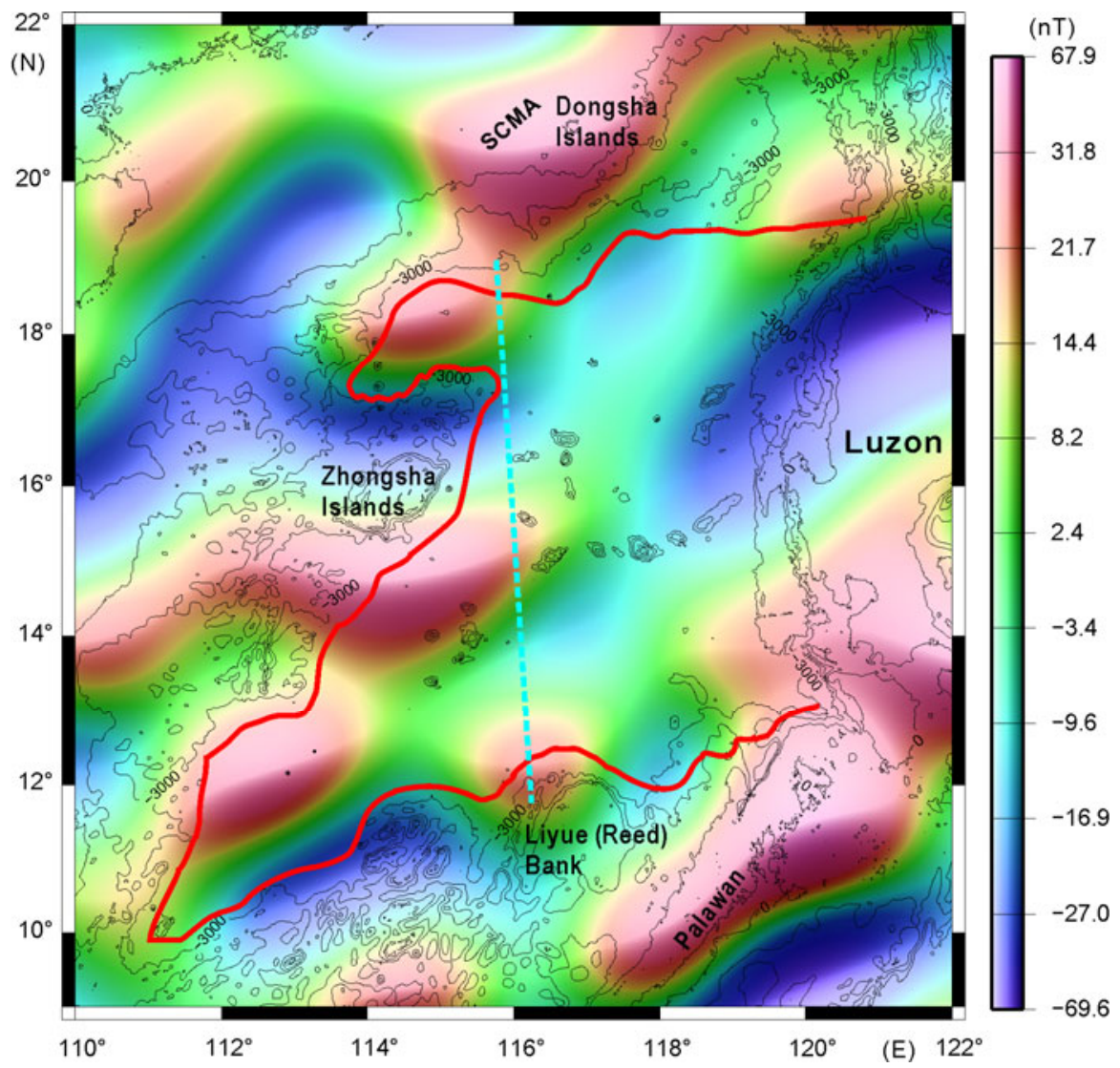

Figure 10 Regional map of satellite magnetic anomalies of the SCS. See Figure 1 for other notations.

zone there $[8,9]$. As we can see today, however, this magnetic quiet zone is not within oceanic crust of the SCS, but within the COT. Apparently, this so-called magnetic quiet zone in the northern SCS continental margin is different in concept from traditionally defined magnetic quiet zone developed within oceanic crusts.

From Figure 1, we see no magnetic quiet zones within the oceanic crust south of the COB. The so-called magnetic quiet zone in the northern SCS continental margin corresponds roughly to the magnetic zones $\mathrm{A}$ and $\mathrm{B}$, but the magnetic anomalies there are no more quiet than those in other areas surrounding the SCS basin. Since the magnetic zone A differs sharply from the magnetic zone B in tectonic affiliations, it is tectonically not meaningful to represent an area composed of blocks of various tectonic affiliations with a single term like magnetic quiet zone.

Through comprehensive analyses and interpretations of a large set of reflection seismic and magnetic data, we find that, within the magnetic zones $\mathrm{A}$ and $\mathrm{B}$, there are well preserved Mesozoic strata [17], which are of large thicknesses and can extend all the way to the COB. We therefore argue that the development of thick Mesozoic strata is the prior cause for the weak magnetic anomalies here. Mesozoic sedimentary rocks recovered from drilling do not bear evidences of strong metamorphism and their magnetic susceptibilities are expected to be neglectable, and therefore the
Mesozoic strata should not induce appreciable magnetic field. Likewise, magnetic susceptibilities of the Cenozoic strata above the Mesozoic are also nearly zero. This allows the magnetic signals to see through the Cenozoic cover, and to be capable of directly characterizing the regional distributions and residues of Cenozoic and Mesozoic strata and even older sedimentary rocks. To further validate this reasoning, we compute 3D analytic signal amplitudes (or total gradient) from magnetic anomalies (Figure 11). In order to reduce the effects of short-wavelength noises, we first upward continue the data by $5 \mathrm{~km}$ before computing 3D analytic signal amplitudes. The biggest advantage of 3D analytic signal amplitudes is that they are capable of accurately delineating positions and boundaries of magnetic sources, while being largely independent of magnetic inclinations [17,58-60]. 3D analytic signal amplitudes further show the existence of a magnetically weak area between the Dongsha Islands and the COB in the northern SCS continental margin, but this area is larger than the area of elevated Curie points and thinned magnetic layer in the COT (Figures 6 and 8 ). Through comprehensive analyses of numerous $2 \mathrm{D}$ reflection seismic sections in the region, we conclude that areas with small 3D analytic signal amplitudes are all well correlated with areas of well preserved Mesozoic strata $[17,61]$, in both of the two conjugate continental margins of the SCS. This supports the argument that it is primarily the 


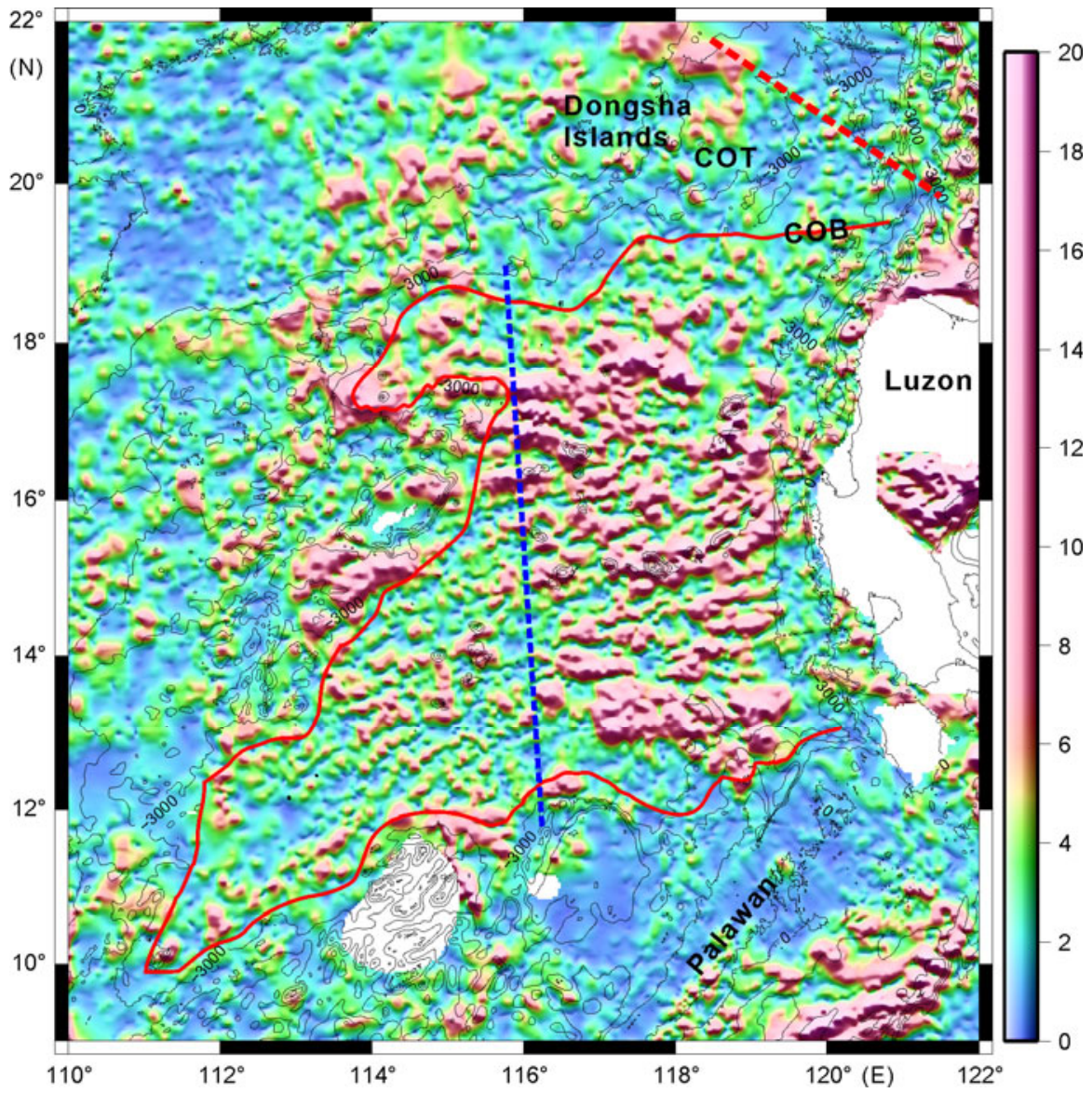

Figure 11 Regional Map of 3D analytical signal amplitudes calculated from regional air-borne and marine magnetic anomalies of the SCS. See Figure 1 for other notations.

development of less susceptive Mesozoic strata that has caused relatively weak magnetic anomalies. Therefore, we can assess potential areas of well developed Mesozoic strata by identifying areas of small 3D analytic signal amplitudes, thereby providing theoretical guidance to hydrocarbon explorations. The small 3D analytic signal amplitudes in the northeast Palawan and Liyue (Reed) Bank have good correspondences to well developed Mesozoic strata either drilled or outcropped there (Figure 11). Apparently, these blocks in the southern SCS margin were connected with Mesozoic blocks in the northern SCS continental margin before the Cenozoic opening of the SCS, forming a large Mesozoic sedimentary basin back then [17,62].

Because 3D analytic signal amplitudes are formulated by taking first-order derivatives in three directions, they are also advantageous in having high resolutions and at the same time being well capable of delineating magnetic boundaries and positions. Therefore, 3D analytic signal amplitudes are well suitable to characterizing shallow magmatic bodies. Seismic data verify that those isolated and small areas of high 3D analytic signal amplitudes in the northern SCS continental margin (Figure 11) are in most cases related to shallow magmatic bodies, which otherwise are not to be easily identified directly from the original total-field magnetic anomaly map (Figure 1). In summary, systematic processing of magnetic anomalies has been critical to understanding both preserved Mesozoic strata and late-stage magmatism.

\section{Conclusion}

We define the continent-ocean boundary (COB) of the SCS through comprehensive analyses of gravimetric, magnetic and reflection seismic data. It is found that the $\mathrm{COB}$ is well correlated to a transitional boundary in free-air gravity anomalies. The area floored with oceanic crust corresponds to an area of mostly positive free-air gravity anomalies, which is generally rimmed by areas or belts of negative free-air gravity anomalies. The transitional boundary from the grossly positive to negative gravity anomalies can define the COB.

With a 2D wavelength-domain cosine-tapered band-pass filter, we cut all wavelength components longer than 200 $\mathrm{km}$ and shorter than $10 \mathrm{~km}$, and pass all wavelength components between $20 \mathrm{~km}$ and $100 \mathrm{~km}$. This operation leads to 
more distinguishable magnetic anomalies caused by seafloor spreading. We find that the oldest identifiable magnetic anomaly caused by seafloor spreading near the northern SCS continental margin is $\mathrm{C} 12(\sim 32 \mathrm{Ma})$, but this anomaly is not identifiable near the southern continental margin. There are still large uncertainties in the opening ages of the Southwest Sub-basin, and we find that computed magnetic anomalies from two different age models can all fit observed anomalies reasonably well. Thus presently available magnetic field data cannot help pinpoint exactly whether the Southwest and East Sub-basins opened simultaneously or in any sequential orders. However, models with a single episode of opening cannot explain the sharp tectonophysical differences across the Zhongnan Fault. Further studies on the spreading history and episode will have to incorporate regional reflection seismic data. Highresolution near-bottom magnetic surveys and deep ocean drilling will be critical to fully solving these problems in oceanic crustal ages and marginal sea evolutions. Patterns in magnetic zonation indicate that the age of magnetic anomalies M1 and M2 (C8, 26 Ma) represents the timing of a key tectonic event during the opening of the SCS. This event could be associated with a change in seafloor spreading rates and/or regional magmatic activities in the SCS. The previously thought ridge jump after $\mathrm{C} 7$ in the east part of the South China Sea may not actually occur.

The Zhongnan Fault and Zhongnan Ridge are important tectonic units in the central SCS basin and reflect themselves well on geophysical fields. The Zhongnan Fault is the boundary between the East and Southwest Sub-basins; the Zhongnan Ridge shows a V-shaped apex and strong internal deformations on reflection seismic sections, and these features could be formed by compression along a fracture zone where strong hydrothermal activities could also develop. Around the Zhongnan Seamounts, both the Curie points and top of the magnetic layer are abnormally shallow, indicating deep active geothermal activities. These findings are conformable with very young magmatism discovered at the Zhongnan Seamounts, and they together suggest that strong late-stage magmatism occurred deep in the Southwest Sub-basin after the cessation of the seafloor spreading. Therefore, the anomalously higher surface heat flow in the Southwest Sub-basin than in the East Sub-basin is possibly linked to stronger late-stage magmatism there, and may not used directly in indicating that the oceanic crust of the Southwest Sub-basin is younger.

The shallowest Curie points in the SCS basin are within the eastern part of the Southwest Sub-basin, and this is known attributable to late-stage magmatism there. In the East Sub-basin, smallest Curie depths tend to occur mostly to the north than to the south of the relict spreading center, implying more intense deep geothermal activities to the north, which are also consistent to stronger late-stage seafloor volcanisms there.

Within the central basin where oceanic crust developed and in the COT of the northern SCS continental margin, Curie points are elevated, and the magnetic layer is appreciably thinner (mostly $<23 \mathrm{~km}$ ) than in the surrounding areas. A magnetized layer of about $10 \mathrm{~km}$ in thickness in the uppermost mantle is identified beneath the SCS, and it can contribute to near surface magnetic anomalies. The regional air-borne and marine magnetic anomalies after filtering with low-pass filters of $300 \mathrm{~km}$ and $400 \mathrm{~km}$ cutoff wavelengths bear high similarities to satellite magnetic anomalies, again confirming that regional near surface magnetic anomalies contain true long-wavelength magnetic anomalies contributed by lower crust and upper mantle magnetic sources.

The so-called magnetic quiet zone in the northern SCS continental margin corresponds roughly to elevated Curie points and thinned magnetic layer, but since this zone is located within COT, it is conceptually very different from traditionally defined magnetic quiet zone developed within oceanic crusts. From integrated analyses of magnetic and reflection seismic data, we find that the area with very well preserved thick Mesozoic strata corresponds clearly with low 3D analytical signal amplitudes calculated from magnetic anomalies. Thick nonmagnetic Mesozoic strata can extend all the way to the COB, and their existence is the main cause for weak and quiet magnetic anomalies there. 3D analytical signal proves to be a very effective tool in detecting distributions of residue Mesozoic strata and latestage magmatic bodies.

This paper benefits from many years of encouragements and supports from Wang Pinxian, Li Jiabiao, and Zhou Zuyi. We thank Lin Jian, Xu Xing, Sun Zhen, Wu Jiansheng, Chen Jun, and Zhang Xinbing for cooperation and assistances. Reflection seismic data were collected by $R / V$ Shiyan-2 of South China Sea Institute of Oceanology, Chinese Academy of Sciences. Geophysical data processing and mapping are facilitated by the USGS potential field software package [63], GMT [64], and Seismic Unix [65]. This work was sponsored by the National Natural Science Foundation of China (91028007 and 40876022), the National Basic Research and Development Program (2007CB411702), and the Research Fund for the Doctoral Program of Higher Education (20100072110036).

1 Cande S V, Kent D V. Revised calibration of the geomagnetic polarity timescale for the late Cretaceous and Cenozoic. J Geophys Res, 1995, 100: 6093-6095

2 Zhu R X, Pan Y X, He H Y, et al. Palaeomagnetism and ${ }^{40} \mathrm{Ar} /{ }^{39} \mathrm{Ar}$ age from a Cretaceous volcanic sequence, Inner Mongolia, China: Implications for the field variation during the Cretaceous normal superchron. Phys Earth Planet Int, 2008, 169: 59-75

3 Courtillot V, Gallet Y, Le Mouël J L, et al. Are there connections between the Earth's magnetic field and climate. Earth Planet Sci Lett, 2007, 253: 328-339

4 Maus S, Kuvshinov A. Ocean tidal signals in observatory and satellite magnetic measurements. Geophys Res Lett, 2004, 31, doi: 10.1029/2004GL020090

5 Blakely R J, Brocher T M, Wells R E. Subduction-zone magnetic anomalies and implications for hydrated forearc mantle. Geology, 2005, 33: 445-448

6 Zhu J, Lin J, Chen Y, et al. A reduced crustal magnetizationzone near the first observed active hydrothermal vent field on the Southwest Indian Ridge. Geophys Res Lett, 2010, doi: 10.1029/2010GL043542

7 Li C-F. An integrated geodynamic model of the Nankai subduction zone and neighboring regions from geophysical inversion and mod- 
eling. J Geodyn, 2011, 51: 64-80

8 Taylor B, Hayes D E. The tectonic evolution of the South China Sea. In: Hayes D E, ed. The Tectonic and Geologic Evolution of South Eastern Asian Seas and Islands, I: Washington D C. Amer Geophys Union Geophys Monogr, 1980, 23: 89-104

9 Taylor B, Hayes D E. Origin and history of the South China Sea basin. In: Hayes D E, ed. The Tectonic and Geologic Evolution of South Eastern Asian Seas and Islands, II. Washington D C. Amer Geophys Union Geophys Monogr, 1983, 27: 23-56

10 Briais A, Patriat P, Tapponnier P. Updated interpretation of magnetic anomalies and seafloor spreading stages in the South China Sea: Implications for the Tertiary tectonics of Southeast Asia. J Geophys Res, 1993, 98: 6299-6328

11 Yao B, Zeng W, Hayes D E, et al. The Geological Memoir of South China Sea Surveyed Jointly by China and USA (in Chinese). Wuhan: China University of Geosciences Press, 1994. 1-204

12 Hsu S K, Yeh Y C, Doo W B, et al. New bathymetry and magnetic lineations identifications in the northeasternmost South China Sea and their tectonic implications. Mar Geophys Res, 2004, 25: 29-44

13 Barckhausen U, Roeser H A. Seafloor spreading anomalies in the South China Sea revisited. In: Clift P, Wang P, Kuhnt W, et al., eds. Continent-Ocean Interactions within East Asian Marginal Seas. AGU Geophys Monogr Ser, 2004, 149: 121-125

14 Jin Z, Xu S, Li Z. Inversion of heterogeneous magnetism for seamounts in the South China Sea (in Chinese). J Ocean Univ Qingdao, 2002, 32: 926-934

15 Geological Survey of Japan and Coordinating Committee for Coastal and Offshore Geoscience Programmes in East and Southeast Asia (CCOP). Magnetic Anomaly Map of East Asia 1:4000000 CD-ROM Version, Digital Geoscience Map 2(P-1), 1996

16 Li C F, Zhou Z, Li J, et al. Structures of the northeasternmost South China Sea continental margin and ocean basin: Geophysical constraints and tectonic implications. Mar Geophys Res, 2007, 28: 59-79

17 Li C-F, Zhou Z, Li J, et al. Magnetic zoning and seismic structure of the South China Sea ocean basin. Mar Geophys Res, 2008, 29: $223-$ 238

18 Hao T, Xu Y, Zhao B, et al. Geophysical research on distribution features of magnetic basements in the South China Sea. Chin J Geophys, 2009, 52: 2763-2774

19 Chen J, Wen N. Geophysical Atlas of the South China Sea. Beijing: Science Press, 2010. 1-137

20 Li C-F, Shi X, Zhou Z, et al. Depths to the magnetic layer bottom in the South China Sea area and their tectonic implications. Geophys J Int, 2010, 182: 1229-1247

21 Franke D, Barckhausen U, Baristeas N, et al. The continent-ocean transition at the southeastern margin of the South China Sea. Mar Petrol Geol, 2011, 28: 1187-1204

22 Gradstein F, Ogg J, Smith A, et al. A Geologic Time Scale 2004. Cambridge: Cambridge University Press, 2004. 1-610

23 Wang P, Prell W L, Blum P, et al. Proceedings of the Ocean Drilling Program, Initial Report 184, College Station, TX: Ocean Drilling Program, 2000

24 Li Q, Jian Z, Li B. Oligocene-Miocene planktonic foraminifer biostratigraphy, Site 1148, northern South China Sea. In: Prell W L, Wang P, Blum P, et al, eds. Proceedings of the Ocean Drilling Program. Scientific Results 184, 2004. 1-26

$25 \mathrm{Su}$ C, Li C-F, Ge H. Characteristics and causes of anomalous reflections on the Oligocene and Miocene transition in the Xihu Depression, East China Sea Basin (in Chinese). J Mar Sci, 2010, 4: 14-21

$26 \mathrm{Ru}$ K, Pigott J D. Episodic rifting and subsidence in the South China Sea. AAPG Bull, 1986, 70: 1136-1155

27 Yao B. Characteristics and tectonic significance of the ZhongnanLiyue Fault (in Chinese). Memoir Geol Res South China Sea, 1995, 7: $1-14$

28 Jin Q. Geology and Hydrocarbon Resources of the South China Sea (in Chinese). Beijing: Geological Publishing House, 1989. 417

29 Song T, Li C F. The opening ages and mode of the South China Sea estimated from high-density magnetic tracks (in Chinese). Prog Geophys, 2012 (in press)
30 Mendel V, Munschy M, Sauter D. MODMAG, a MATLAB program to model marine magnetic anomalies. Compu Geosci, 2005, 31: 589-597

31 Wu H H, Tsai Y B, Lee T Y, et al. 3-D shear wave velocity structure of the crust and upper mantle in South China Sea and its surrounding regions by surface wave dispersion analysis. Mar Geophys Res, 2004, 25: 5-27

32 Qiu X, Chen R, Zhu R, et al. The application of large volume airgun sources to the onshore-offshore seismic surveys: Implication of the experimental results in northern South China Sea. Chin Sci Bull, 2007, 52: 463-469

33 Jin Z, Xu S, Li Q. The development and paleomagnetics of seamounts in the subbasin of the South China Sea, China. Acta Oceanol Sin, 2004, 26: 83-93

34 Ding W, Chen H, Yang S, et al. Apply the interpolation cut method in magnetic anomaly analyses of the South China Sea. J Zhejiang Univ, 2003, 30: 223-229

35 Braitenberg C, Wienecke S, Wang Y. Basement structures from Satellite Derived Gravity Field: The South China Sea ridge. J Geophys Res, 2006, 111, doi: 10.1029/2005JB003938

36 Wang T K, Chen M K, Lee C S, et al. Seismic imaging of the transitional crust across the northeastern margin of the South China Sea. Tectonophysics, 2006, 412: 237-245

37 Zhao M H, Qiu X L, Xia S H, et al. Seismic structure in the northeastern South China Sea: S-wave velocity and $V_{\mathrm{p}} / V_{\mathrm{s}}$ ratios derived from three-component OBS data. Tectonophysics, 2010, 480: 183197

38 Dyment J, Arkani-Hamed J, Ghods A. Contribution of serpentinized ultramafics to marine magnetic anomalies at slow and intermediate spreading centres: Insights from the shape of the anomalies. Geophys J Int, 1997, 129: 691-701

39 Vine F J, Matthews D H. Magnetic anomalies over oceanic ridges. Nature, 1963, 199: 947-949

40 Blakely R J. Random crustal magnetization and its effect on coherence of short-wavelength marine magnetic anomalies. Earth Planet Sci Lett, 1979, 46: 43-48

41 Banerjee S K. The magnetic layer of the ocean crust-how thick is it? Tectonophysics, 1984, 105: 15-27

42 Furuta T, Fujimoto H, Toh H. Is the oceanic crust over $1 \mathrm{~km}$ necessary for the source of marine magnetic anomalies? Phys Earth Planet Inter, 1987, 49: 117-120

43 Arkani-Hamed J. Thermoremanent magnetization of the oceanic lithosphere inferred from a thermal evolution model: Implications for the source of marine magnetic anomalies. Tectonophysics, 1991, 192: $81-96$

44 Kikawa E, Ozawa K. Contribution of oceanic gabbros to sea-floor spreading magnetic anomalies. Science, 1992, 258: 796-799

45 Shau Y H, Peacor D R, Essene E J. Formation of magnetic singledomain magnetite in ocean ridge basalts with implications for seafloor magnetism. Science, 1993, 269: 343-345

46 Chen Y J. Oceanic crustal thickness versus spreading rate. Geophys Res Lett, 1992, 19: 753-756

47 Morgan J P, Chen Y J. The genesis of oceanic crust: Magma injection, hydrothermal circulation, and crustal flow. J Geophys Res, 1993, 98: 6283-6297

48 Tivey M A. Vertical magnetic structure of ocean crust determined from near-bottom magnetic field measurements. J Geophys Res, 1996, 101: 20275-20296

49 Gee J, Cande S V, Hildebrand J A, et al. Geomagnetic intensity variations over the past $780 \mathrm{kyr}$ obtained from near-seafloor magnetic anomalies. Nature, 2000, 408: 827-832

50 Sayanagi K, Nishimura, Joshima M, et al. Deep-tow magnetic anomaly near ODP Site 795 in the northeastern margin of the Japan Basin. Proc Jpn Acad, 2001, 77: 57-62

51 Tivey M A, Johnson H P. Crustal magnetization reveals subsurface structure of Juan de Fuca. Geology, 2002, 30: 979-982

52 Zhao J, Zhang Y. Deep structure and genetic model of magnetic quiet zone. Shanghai Geol, 2008, 29: 4-7

53 Zhao J, Shi X, Qiu X, et al. Characteristics and petroleum geological 
significance of Curie point isotherm in the northeastern South China Sea. J Trop Oceanogr, 2010, 29: 126-131

54 Gao J, Wu Z, Wang J, et al. Review of researches on the magnetic quiet zone at the northern continental margin of the South China Sea and its comparison with those in the global oceans. Adv Earth Sci, 2009, 6: 577-587

55 Hao T, Huang S, Xu Y, et al. Comprehensive geophysical research on the deep structure of Northeastern South China Sea. Chin J Geophys, 2008, 51: 1785-1796

56 Zhou D, Sun Z, Chen H Z, et al. Mesozoic paleogeography and tectonic evolution of South China Sea and adjacent areas in the context of Tethyan and Paleo-Pacific interconnections. Island Arc, 2008, 17: 186-207

57 Barrett D L, Keen C E. Mesozoic magnetic lineations, the magnetic quiet zone and sea floor spreading in the northwest Atlantic. J Geophys Res, 1976: 4875-4884

58 Nabighian M N. Toward a three-dimensional automatic interpretation of potential field data via generalized Hilbert transforms-Fundamental relations. Geophysics, 1984, 49: 780-786
59 Ofoegbu C O, Mohan N L. Interpretation of aeromagnetic anomalies over part of southeastern Nigeria using three dimensional Hilbert transformation. Pure Appl Geophys, 1990, 134: 13-29

60 Roest W R, Verhoef J, Pilkington M. Magnetic interpretation using the 3-D analytic signal. Geophysics, 1992, 57: 116-125

61 Shi H, Li C F. Mesozoic and early Cenozoic tectonic convergenceto-rifting transition prior to the opening of the South China Sea. Int Geol Rev, 2012, doi:10.1080/00206814.2012.677136

62 Li C F, Zhou Z, Hao H, et al. Late Mesozoic tectonic structure and evolution along the present-day northeast South China Sea continental margin. J Asian Earth Sci, 2008, 31: 546-561

63 Cordell L, Phillips J D, Godson R H. USGS potential-field geophysical software for PC and compatible microcomputers. Leading Edge, 1993, 12: 290

64 Wessel P, Smith W H F. New version of the Generic Mapping Tools (GMT) version 3.0 Released. Trans AGU EOS, 1995, 76: 329

65 Cohen J K, Stockwell J W. CWP/SU: Seismic Unix Release 36: A free package for seismic research and processing. Center for Wave Phenomena, Colorado School of Mines, 2002

Open Access This article is distributed under the terms of the Creative Commons Attribution License which permits any use, distribution, and reproduction in any medium, provided the original author(s) and source are credited. 